RESEARCH PAPER RP1588

\author{
Part of Journal of Research of the National Bureau of Standards, Volume 32, \\ June 1944
}

\title{
PURIFICATION OF SUBSTANCES BY SLOW FRACTIONAL FREEZING
}

\author{
Frank W. Schwab and Edward Wichers
}

\section{ABSTRACT}

This paper describes two technics for purifying substances by slow fractional freezing.

The first involves the slow lowering of a cylindrical cell, filled with the fused substance, through a heating coil in such a way that freezing begins at the bottom and progresses upward, as the cell emerges from the coil, until the whole mass has solidified. The solidified column, tube and all, is cut into the desired fractions.

The second technic, which is suitable for larger quantities, affords better control of the rate of freezing and provides a larger solid-liquid surface for a given quantity of material. A spherical flask filled with the liquid is cooled at a controlled rate in such a way that freezing begins at the wall of the flask and proceeds inward at a regulated slow rate until the desired fraction has solidified, after which the remaining liquid is siphoned out of the flask.

The purification of benzoic acid was much more rapid by this method than in earlier trials by crystallization from solvents. Acetanilide was also effectively purified. Observations incidental to the work show that the freezing point of pure acetanilide is $114.29 \pm 0.01^{\circ} \mathrm{C}$.

In an earlier paper ${ }^{1}$ brief reference was made to the use of fractional freezing as a means of purifying benzoic acid. This work was done on a very small scale. It followed closely a technic previously used by R. S. Jessup, of the Heat Measurements Section of this Bureau. A cylindrical tube, $2 \mathrm{~cm}$ in diameter, containing $50 \mathrm{~g}(45$ to $50 \mathrm{ml})$ of the fused acid (mp 122.4 $\mathrm{C}$ ) was slowly lowered through a heating coil. As the tube emerged from the coil, freezing began at the bottom and progressed until the whole mass was frozen. During the freezing, which extended over a period of 6 hours, the liquid portion was constantly stirred.

The foregoing procedure was also used to purify benzoic acid on a larger scale, for quantities of about $500 \mathrm{~g}$. The glass tubes used were $4.6 \mathrm{~cm}$ in diameter, and the column of molten acid was about $30 \mathrm{~cm}$ long. The tube was lowered through the heating coil by supporting it on a platform floating in a tank of water, as shown in figure 1 . Water was allowed to flow slowly from the tank through an outlet valve on a lower floor of the building. This was done to keep the hydraulic head substantially constant. Some difficulty was experienced with stoppage of the needle valve by particles of dirt. Alto- 
gether, there were enough minor problems in operating this mechanically simple device to suggest that a somewhat more elaborate arrangement, such as a clock- or motor-driven movement, would have proved more satisfactory.

The liquid portion of the acid was stirred with a stream of nitrogen gas flowing from a Branham-Sperling bubbler. ${ }^{2}$ The total period of

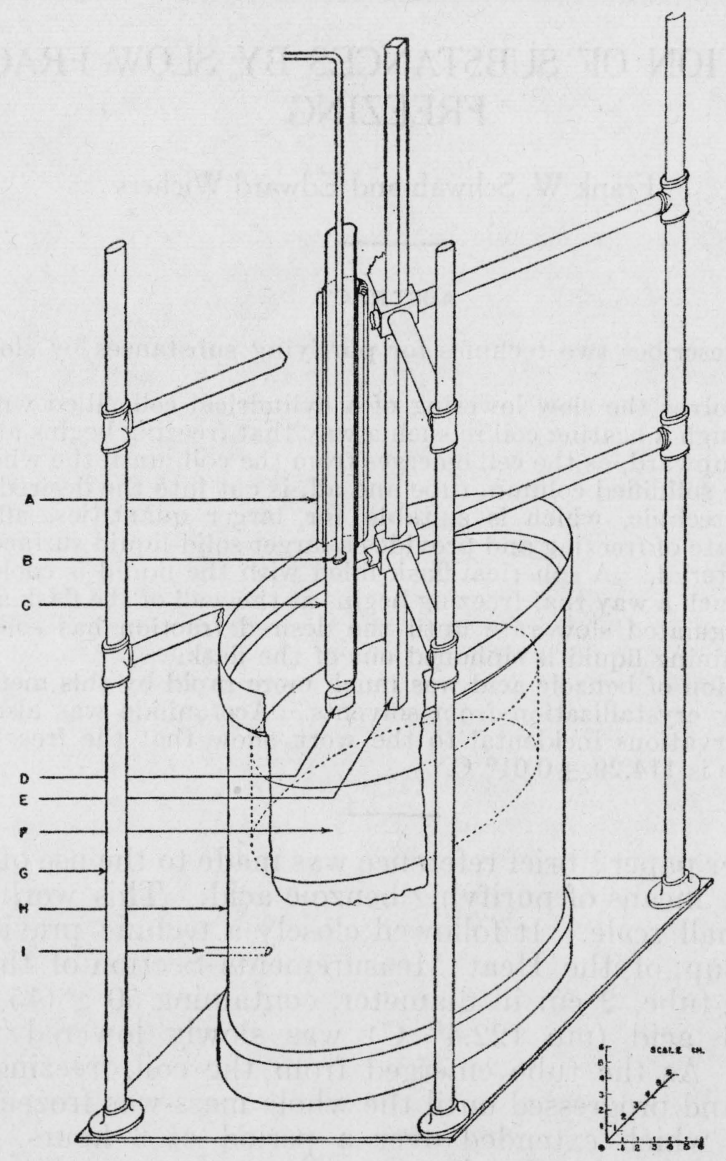

FIGURE 1.-Sketch of apparatus for the purification of a substance by slow fractional freezing in a cylindrical cell

A, Heating element backed by a layer of insulating material supported on an open Pyrex cylinder; B, a Branham-Sperling bubbler tip for stirring with nitrogen; C, cylindrical cell; D, cork support for cell; $\mathrm{E}$, float guide; F, float; $\mathrm{G}$, supports; H, container for water; and I, water outlet.

freezing was from 16 to 20 hours. An advantage of this method is that the acid is readily separated into fractions by allowing all of it to freeze and then cutting the column, tube and all, into suitable lengths.

A quantity of benzoic acid, which had an initial purity of 99.91 mole percent, was fractionally frozen three times in this apparatus, and each time the last one-fourth frozen was discarded. The yield of purified acid thus was about 40 percent. Its purity was 99.997 mole

\footnotetext{
$2 \mathrm{~J}$. R. Branham and E. O. Sperling, Bubbler tip of Pyrex glass for difficult absorptions, J. Research NBS 22, 701 (1939) RP1214.
} 
percent, as determined by measuring its freezing range in the manner described in an earlier publication. ${ }^{3}$

In the study of a process of this sort, it is helpful to know what fraction of the total impurity is removed by a single operation, in this case, a single crystallization. This fraction will be referred to as the efficiency of the process of purification. The over-all increase in purity can be used to calculate the efficiency of the process of purification. In this instance the substance contained, in 100,000 moles of starting material, 90 moles of impurities susceptible of removal by fractional freezing. After the third step of fractionation, the content of impurities was 3 moles in 100,000 , or 3.3 percent of the amount originally present. Assuming equal efficiency of separation in all three steps of purification, the fraction of impurity not removed in a single step is the cube root of 0.033 ; that is, 0.32 . The average efficiency of purification in this instance was therefore 68 percent.

When benzoic acid was fractionally frozen in the manner described, the solid material was clear and did not show evidence of entrapment of liquid or other macroscopic contamination. It seems probable that the relatively low efficiency of purification was caused by failure to maintain equilibrium at the solid-liquid interface. This could result from irregularities in the seemingly smooth progress of the cell through the heating coil, from irregular cooling caused by drafts or temperature changes around the apparatus, or simply from too rapid freezing. As freezing takes place the impurities increase in concentration in the very thin layer of liquid immediately adjacent to the solid surface. It is well known that this layer is not mixed with the body of the liquid by stirring, hence impurities can be transferred from it to the body of the liquid only by diffusion. It seems evident therefore that the degree of approach to ideal separation of impurities must be a function of the rate of deposition of crystalline material per unit area of surface.

Instead of attempting to improve the relative efficiency of purification by freezing in cylindrical cells, another apparatus was prepared in which the area of freezing surface was larger in relation to the quantity of material to be frozen, and the rate of freezing could be more steadily maintained and more easily regulated. In this apparatus it was possible also to handle much larger quantities than can well be done in cylindrical vessels. The apparatus is shown in figures 2 and 3. It consisted essentially of a long-necked, 5-liter flask of Pyrex glass imbedded in an especially effective thermal insulating material, silica aerogel, containing about 15 percent of silicon, ${ }^{4}$ and provided with a small resistance heater wound around the base of the neck. The flask was filled with molten benzoic acid at a temperature about $10^{\circ} \mathrm{C}$ above its freezing point, enough to allow the loss of heat to the surroundings to become steady before freezing began. The liquid was agitated with a glass stirrer. ${ }^{5}$ The stem of the stirrer passed through a hole in the flat bottom of a glass cylinder which closely fitted the neck of the flask, and which was placed with its

\footnotetext{
${ }^{3}$ F. W. Schwab and Edward Wichers, Precise Measurement of the Freezing Range as a Means of Determining the Purity of a Substance, Temperature-Its Measurement and Control in Science and Industry, p. 256-264 (Reinhold Publishing Corporation, New York, N. Y., 1941).

The impurities measured by the freezing range are limited to those soluble in the liquid but insoluble in the crystals. The same limitation applies, of course, to a process of purification based on fractional freezing. Ind. Eng. Chem. 31, 827 (1939).

5 The glass stirrer is made by sealing two rectangular flats about $1 \mathrm{~cm}$ by $6 \mathrm{~cm}$ to a glass rod. The long edges of the flats are centered and sealed to opposite sides of the rod, forming an angle at 20 to 25 degrees with it. A stirrer of this type vibrates less than the usual propeller type. The authors are indebted to W. G. Schlecht for the design of this stirrer.
} 
bottom near the upper end of the resistance heater. The bottom of the sleeve formed a baffle to prevent loss of heat by convection in the neck of the flask and also sublimation of the acid into the neck. As the flask was imbedded in insulating material to a point above the heater on the neck, heat could be added to the system at this point to regulate to a limited extent the net loss of heat from the body of the flask. With the heater furnishing 5.8 watts, the rate of total loss

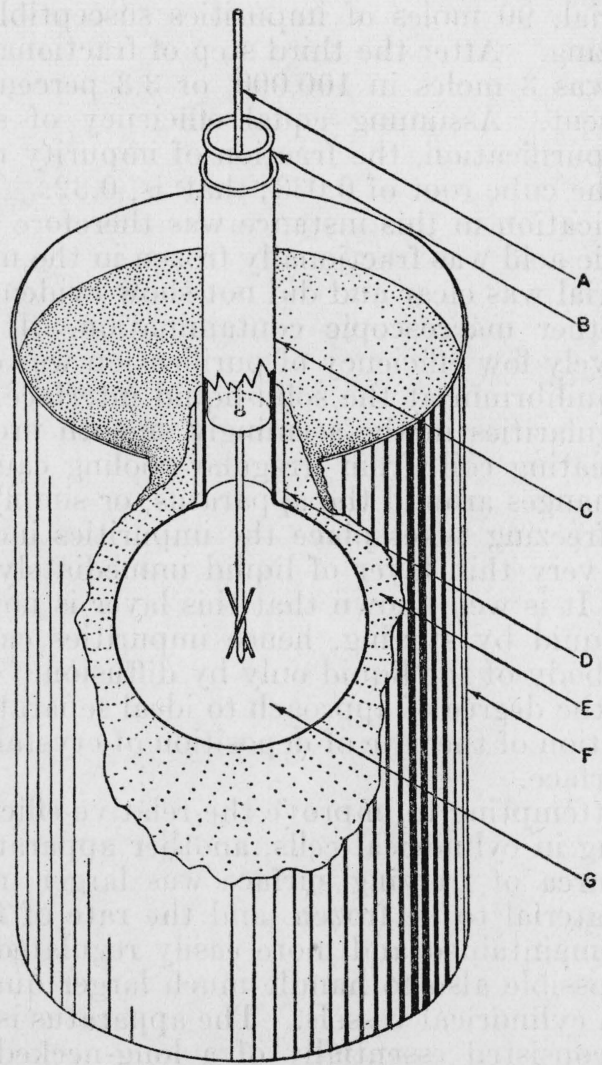

Figure 2.-Apparatus for the purification of a substance by slow fractional freezing in a round-bottom flask.

A, glass stirrer; B, sleeve to prevent loss of heat by convection; C, five-liter flask; D, heater for balancing the loss of heat through the neck of the flask; E, insulating material (silica aerogel); F, container for insulating material; and $G$, substance being purified.

of heat from the flask was about 7.5 watts, as determined from the amount of benzoic acid frozen and the latent heat of fusion. The rate of loss of heat was also roughly determined by the rate at which the liquid benzoic acid cooled just before it began to freeze.

After the desired fraction of the acid was frozen, the stirring assembly was removed and the remaining liquid was drawn off by suction. Then, a point-source radiant heater in the form of a small 45-watt lamp (automobile headlight type), with its electrical leads enclosed in a glass tube, was lowered through the neck to the center of the flask. Since benzoic acid is nearly opaque to red and infrared radiation, the heat from the lamp caused the surface layer of the acid 
to melt. About 15 minutes' exposure to the lamp was required to melt $100 \mathrm{~g}$. The surface of the solid which had been in contact with the impure mother liquor was thus washed by drawing off the remelted portion. This washing was done three times. The solid acid formed a nearly uniform layer about $2.8 \mathrm{~cm}$ thick over the whole inside of the flask except that it was thinner near the neck, where the level of the liquid had subsided because of the reduction in volume which occurred during freezing. The acid was nearly transparent except for shrinkage cracks which developed on cooling to room temperature.

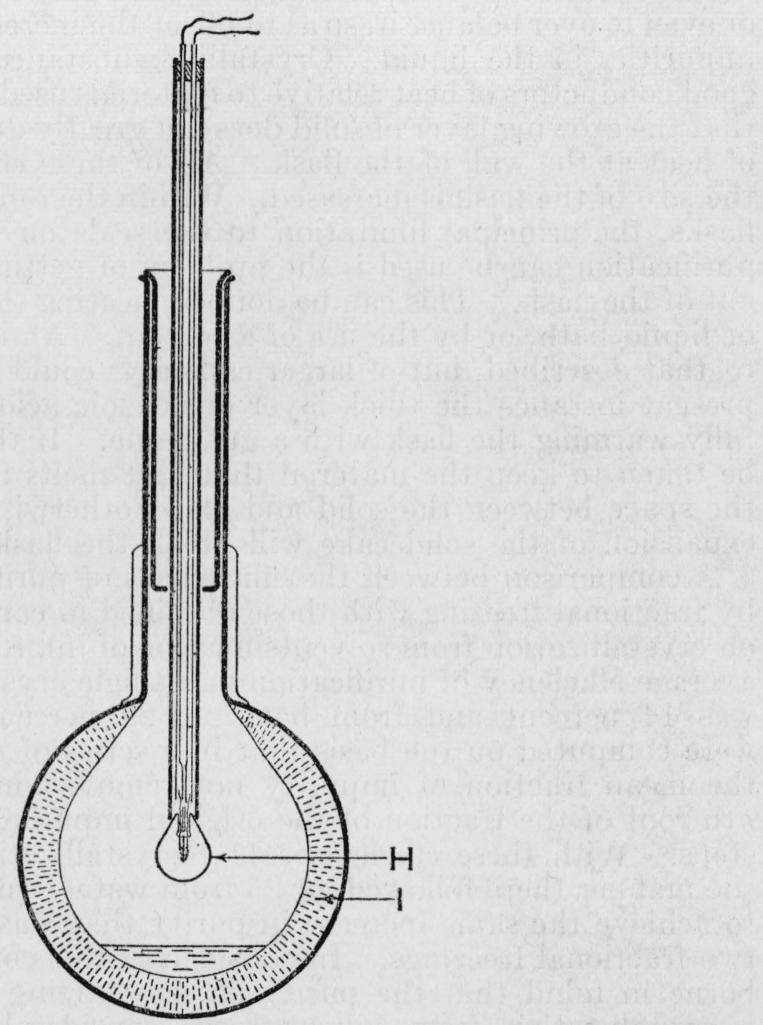

FiguRe 3.-Assembly for partial melting and washing of crystallized material. $\mathrm{H}$, Radiant heater; I, layer of crystals.

In the foregoing manner about $10 \mathrm{~kg}$ of benzoic acid was twice frozen, each time rejecting about 40 percent of the quantity in the flask. The combined products of the first fractionation of two 5-kg lots thus yielded more than enough to fill the flask for the second fractionation. The average purity of the product of the first fractionation was 99.986 mole percent and that of the second 99.998 mole percent. Since the starting material had a purity of 99.91 mole percent, it will be seen that the relative efficiency of separation was about 85 percent in each step. This figure is comparable with the efficiency of 68 percent reported for the cylindrical cell, because nearly the same fraction was rejected. It represents a marked gain in efficiency. This is attributable in part, perhaps, to a steadier rate of freezing, but 
dmainly to a slower rate of freezing. In the flask this was approxidnately $0.18 \mathrm{~g} / \mathrm{cm}^{2}$ of crystallizing surface per hour (a rate of growth fof $0.024 \mathrm{~mm}$ per minute), whereas in the cylindrical cell it was 1.25 $\mathrm{I} / \mathrm{cm}^{2}$ of crystallizing surface per hour. It is obvious that, for any given quantity of liquid to be frozen, the use of the whole surface of a spherical container as a solid-liquid interface offers a marked advanthage over freezing at one end surface in a cylindrical vessel. It is true that as freezing progresses in the flask the surface exposed to the liquid becomes smaller, thereby increasing the rate of freezing per unit area. However, the rate of loss of heat can be decreased to balance this change, or even to over balance it, so as to offset the increasing concentration of impurities in the liquid. Crystalline substances in general are such good conductors of heat relative to materials used for thermal insulation that the growing layer of solid does not greatly decrease the rate of loss of heat at the wall of the flask. All of these effects are decreased as the size of the flask is increased. Within the range of available sizes of flasks, the principal limitation to the scale on which this method of purification can be used is the problem of getting the frozen material out of the flask. This can be done by heating the whole flask in an air or liquid bath, or by the use of a solvent. An internal heater similar to that described, but of larger capacity, could also be used. In the present instance the thick layer of benzoic acid was melted by carefully warming the flask with a gas flame. If this is done, care must be taken to keep the material that first melts from freezing again in the space between the solid and glass, otherwise subsequent thermal expansion of the solid cake will break the flask.

A comparison between the efficiencies of purification here obtained by fractional freezing with those obtained in earlier work (footnote 1) on crystallization from solvents may be of interest. In that work the average efficiency of purification in a single crystallization from water was 14 percent and from benzene, 29 percent. These efficiencies were computed on the basis that in a series of $n$ steps of purification the mean fraction of impurity not removed in a single step is the $n$th root of the fraction of the original impurity that remains after $n$ steps. With these efficiencies 11 recrystallizations from benzene, in the manner there followed, or 25 from water, would have been needed to achieve the same increase in purity that was accomplished by the two fractional freezings. In considering this comparison it should be borne in mind that the purity of the starting material used in the recrystallization from solvents was considerably higher than that used for the fractional freezing and that the character of the impurities was not necessarily the same. It should also be noted that the efficiencies in question do not necessarily represent the highest that could Be obtained by the respective methods.

or The apparatus used for benzoic acid was also used (by W. H. Smith and W. W. Walton, of this Bureau) to purify a quantity of bacetanilide. A single fractionation, in which about 50 percent was Pejected, resulted in an increase in purity from 99.80 mole percent o(determined from its freezing range) to 99.98 mole percent. The relative efficiency of purification therefore was 90 percent. In this Jihstance the solid acetanilide was removed from the flask by dissolving Tit in hot benzene. On cooling the benzene solution the acetanilide of Purity of the product therefore involved one step of crystallization 
from benzene in addition to the fractional freezing. It was determined after removing the benzene trapped by the crystals. The extent of this incidental contamination by the solvent amounted to 0.11 percent for the crystals as dried at room temperature and 0.05 percent after the crystals were crushed somewhat. The amount of solvent in the substance was determined by a method, developed by the authors ${ }^{6}$ for determining water and other volatile material in pure substances. The freezing temperature of this product, after removing benzene from it, was $114.28^{\circ} \mathrm{C}$. The purity of the substance and the accuracy of the measurement of the temperature were sufficient to warrant giving $114.29^{\circ} \pm 0.01^{\circ} \mathrm{C}$ as the freezing temperature of pure acetanilide.

It is believed that slow fractional freezing deserves more consideration as a means of purification than it has received heretofore for substances stable at temperatures somewhat above their freezing points. The slow and steady rate of crystal growth that can be maintained offers a marked advantage over crystallization from solvents, as commonly practiced, with respect to approaching equilibrium between the solid and liquid phases. The method need not be limited to substances which freeze above room temperature. It should be equally applicable, with a suitable refrigerant, to substances which freeze at lower temperatures.

The authors express their appreciation to C. L. Gordon for the preparation of the drawings appearing in this paper.

Washington, April 1, 1944.

\footnotetext{
'A sample of acetanilide was fused in a glass apparatus, which was evacuated through a trap immersed in liquid air. The trap was then closed off from the rest of the apparatus, and the liquid air was removed, allowing the trap to warm up to room temperature. The amount of benzene removed from the acetanilide was estimated from the pressure, measured by means of a mercury manometer, and the temperature and volume of the closed system.
} 